\title{
Centroid-moment-tensor analysis of the 2011 off the Pacific coast of Tohoku Earthquake and its larger foreshocks and aftershocks
}

\author{
Meredith Nettles, Göran Ekström, and Howard C. Koss \\ Lamont-Doherty Earth Observatory, Columbia University, USA
}

(Received April 7, 2011; Revised May 23, 2011; Accepted June 4, 2011; Online published September 27, 2011)

\begin{abstract}
Centroid moment tensors (CMTs) for the March 11, 2011, off the Pacific coast of Tohoku Earthquake and its larger foreshocks and aftershocks are presented. The CMTs are calculated using long-period data from the Global Seismographic Network retrieved in near-real time, and the inversion algorithm employed in the Global CMT Project. Owing to its large size and long duration, the mainshock CMT analysis is performed at periods longer than $300 \mathrm{~s}$. The resulting moment tensor has a scalar moment of $5.3 \cdot 10^{29}$ dyne-cm, and a geometry that indicates thrust motion of the Pacific Plate beneath the island of Honshu on a plane dipping $10^{\circ}$. The large scalar moment, translating to moment magnitude $M_{\mathrm{W}}=9.1$, makes this the fourth largest earthquake in the last 100 years. The mainshock was preceded by several large foreshocks with similar underthrusting mechanisms, the largest of which having $M_{\mathrm{W}}=7.4$. The aftershock sequence extends over a portion of the plate boundary more than $500 \mathrm{~km}$ long, and exhibits an unusual diversity of faulting geometries. Reverse, normal, and strike-slip faulting events with widely varying directions of maximum tension and compression occur throughout the upper plate. A $M_{\mathrm{W}}=7.9$ aftershock occurred near the southern end of the aftershock zone approximately 30 minutes after the mainshock, and is, at the time of writing, the largest aftershock in the sequence. The second-largest aftershock is a $M_{\mathrm{W}}=7.6$ normal-faulting outer-rise earthquake that occurred 40 minutes after the mainshock.
\end{abstract}

Key words: Centroid moment tensor, Tohoku Earthquake, subduction, aftershock.

\section{Introduction}

The great off the Pacific coast of Tohoku Earthquake of March 11, 2011, was one of the largest earthquakes of the past century and the largest well-documented earthquake to strike Japan. The earthquake was preceded by a number of foreshocks, the largest of which being a $M_{\mathrm{W}}=7.4$ event on March 9. The $M_{\mathrm{W}}=9.1$ mainshock has been followed by intensive aftershock activity offshore of a 500-km-long portion of the eastern Honshu coast, as well as by moderatesize earthquakes on the west side of Honshu.

The shallow-thrusting focal mechanism of the mainshock reflects the relative motion of the subducting Pacific plate and the overriding North America plate. The foreshocks and approximately half of the aftershocks show similar faulting geometries, and their locations are generally consistent with rupture on the same plate-boundary fault as the mainshock. A significant number of aftershocks are, however, not associated with slip on the plate boundary, but occur on intraplate faults of a variety of orientations. These earthquakes likely reflect the long-term internal deformation patterns of the plates as well as coseismic stress changes associated with the mainshock. Their focal geometries and spatial distribution are therefore important for constraining and confirming both of these.

In this paper, we present the results of a systematic

Copyright (C) The Society of Geomagnetism and Earth, Planetary and Space Sciences (SGEPSS); The Seismological Society of Japan; The Volcanological Society of Japan; The Geodetic Society of Japan; The Japanese Society for Planetary Sciences; TERRAPUB.

doi:10.5047/eps.2011.06.009 moment-tensor analysis of the larger $(M>5.5)$ earthquakes in the 2011 Tohoku Earthquake sequence, and characterize the aftershock sequence in terms of earthquake locations and focal geometries.

\section{Analysis and Results}

We use the standard methods and algorithms of the Global CMT Project to determine moment tensors of the Tohoku sequence (Dziewonski et al., 1981; Arvidsson and Ekström, 1998; Ekström et al., 2005). In these methods, the moment tensor and source centroid are estimated by matching observed long-period three-component seismograms to synthetic waveforms calculated by summation of Earth's normal modes.

In the case of the 2011 Tohoku Earthquake, and of other great earthquakes with intense aftershock sequences, the analysis is complicated by the mainshock's strong excitation of long-period, slowly attenuating overtone modes, as well as the superposition of high-amplitude surface-wave signals from large and frequent aftershocks. Both of these factors raise the amplitude of the background noise, and make it difficult to isolate waveforms that can be clearly attributed to a particular earthquake of interest. Careful selection of appropriate time windows to be included in the source inversion is in some cases essential for obtaining a robust result.

We use data from the Global Seismographic Network (GSN) acquired in near-real time in the analysis. For many of the events, the waveforms selected for inversion are primarily minor-arc intermediate-period ( $50-150 \mathrm{~s}$ period) 


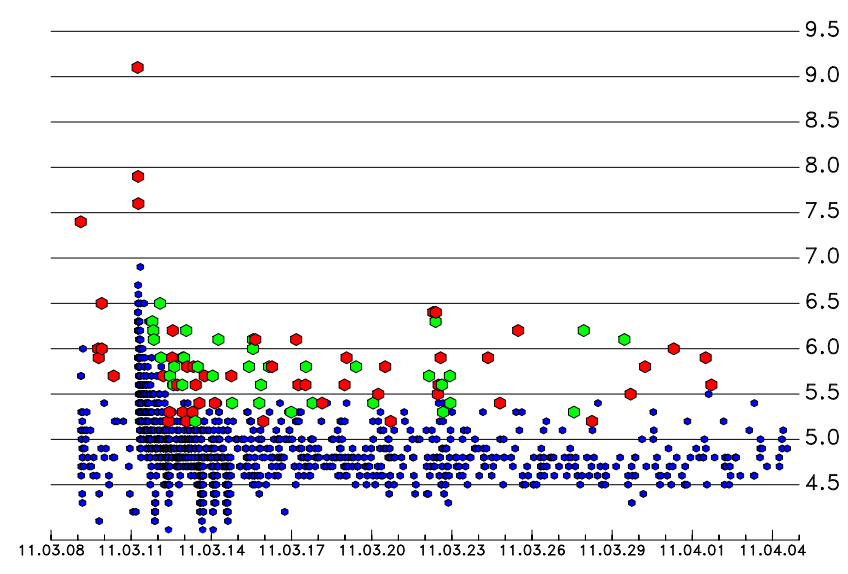

Fig. 1. Times and magnitudes of earthquakes in the 2011 Tohoku Earthquake sequence. Small blue symbols show times and magnitudes for all earthquakes reported by the USGS NEIC (data downloaded on 2011-04-06). Red and green symbols show moment magnitudes for earthquakes analyzed in this study. Red symbols denote conforming mechanisms, consistent with either interplate thrusting or outer-rise extension. Green symbols denote other, non-conforming, intraplate earthquakes in the overriding plate.

surface waves, since these arrivals are typically of high amplitude and well defined in the seismograms.

The event selection for the analysis presented here was based on the magnitudes reported by the USGS NEIC right after the events occurred. We selected for analysis all events with reported magnitudes greater than or equal to 5.5. We augmented the list of earthquakes selected for analysis with events detected using long-period surface waves (Ekström, 2006; www.globalcmt.org). Many events that occurred during the first 24 hours following the mainshock could not be successfully analyzed, due to the strong residual signals from the mainshock and subsequent large aftershocks. However, we were able to determine robust moment-tensor solutions for 88 earthquakes during the period starting with the foreshocks on March 9 through 25 days following the March 11 mainshock (April 4). Figure 1 shows the time of occurrence and magnitude of each earthquake analyzed in this study.

\subsection{Foreshocks}

On March 9, the first large earthquake in the Tohoku sequence occurred. The seismic activity that followed over the subsequent 51 hours can retrospectively be identified as a foreshock sequence. We calculated CMT solutions for six of the largest earthquakes in the foreshock sequence, and their locations and focal mechanisms are shown in Fig. 2. The six focal mechanisms are consistent with underthrusting motion of the Pacific plate. The first earthquake in the foreshock sequence, at 02:45:20.3, is the largest, with a moment magnitude of $M_{\mathrm{W}}=7.4$. Its epicenter is close to the source regions of earlier large earthquakes off the coast of Miyagi Prefecture, notably the $M_{\mathrm{W}}=7.6$ earthquake of June 12,1978 , and the $M_{\mathrm{W}}=7.2$ earthquake of August 16, 2005.

The second-largest event of the foreshock sequence, a $M_{\mathrm{W}}=6.5$ earthquake on March 9 at 21:24:08.0, is the only earthquake analyzed in this study for which there was no NEIC detection, and we relied on our surface-wave de-

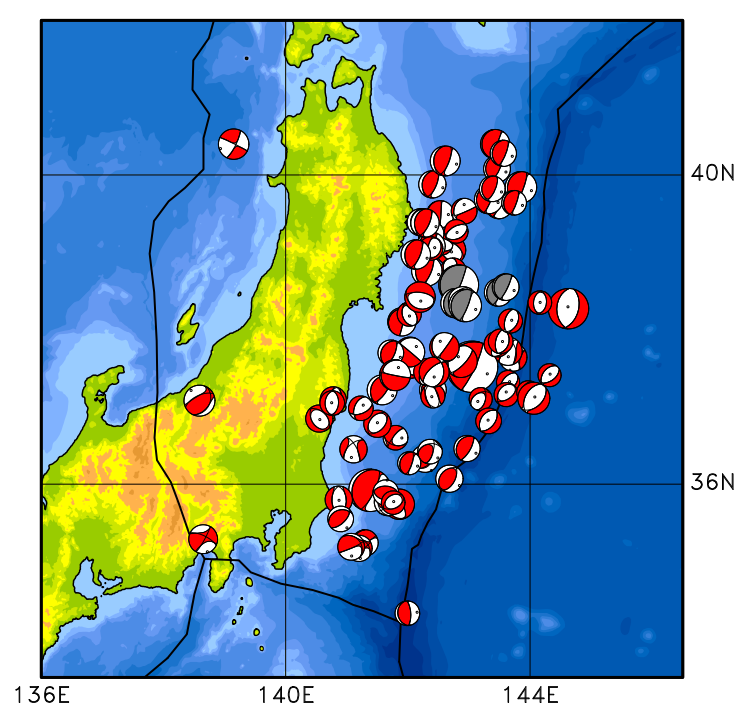

Fig. 2. Map showing 88 focal mechanisms determined in this study. Symbols are plotted at the centroid locations, and their size is proportional to the moment magnitude. Gray focal mechanisms correspond to the six large foreshocks of the March 11 mainshock. Plate boundaries are from Bird (2003).

tection of this event to initiate the CMT analysis. The earthquake followed closely a $M_{\mathrm{W}}=6.0$ earthquake at 21:22:18.1, and the higher-frequency $P$ phases may have been obscured in the coda of that event.

\subsection{Mainshock}

The epicenter of the March 11, 05:46:24.7 mainshock lies approximately $40 \mathrm{~km}$ southwest of the foreshocks. The large rupture area and duration of the mainshock make it necessary to limit the CMT analysis to very long periods. We performed inversions in several different period bands between $200 \mathrm{~s}$ and $1000 \mathrm{~s}$, obtaining consistent results in the different inversions. Our preferred solution was obtained using 8.5-h-long seismograms from 100 stations of the GSN filtered between $300 \mathrm{~s}$ and $500 \mathrm{~s}$. The centroid time, reflecting the time-averaged center of moment, is shifted approximately $70 \mathrm{~s}$ after the hypocentral time, indicating a compact moment-rate distribution. The spatial centroid of moment is located $\sim 110 \mathrm{~km} \mathrm{SE}$ and up dip of the epicenter. The moment tensor corresponds to an essentially pure doublecouple mechanism with strike $203^{\circ}$, dip $10^{\circ}$, and rake $88^{\circ}$. The seismic moment is $5.3 \cdot 10^{29}$ dyne-cm, corresponding to moment magnitude $M_{\mathrm{W}}=9.1$. We performed a number of experiments to examine the robustness of these results, in particular the seismic moment. Varying the filter parameters and constraining the centroid depth at deeper or shallower depths resulted in moment magnitudes in the range 9.03-9.16.

In an additional test to investigate the ability of the CMT point-source parameters to explain the longest-period seismic waves, we filtered the observed and synthetic waveforms corresponding to our preferred result in the period band 500-1000 seconds, outside of the period band used in the inversion. Figure 3 shows the fits at representative stations, including both vertical and horizontal components. Both very-long-period Love waves and Rayleigh waves are well fit. 


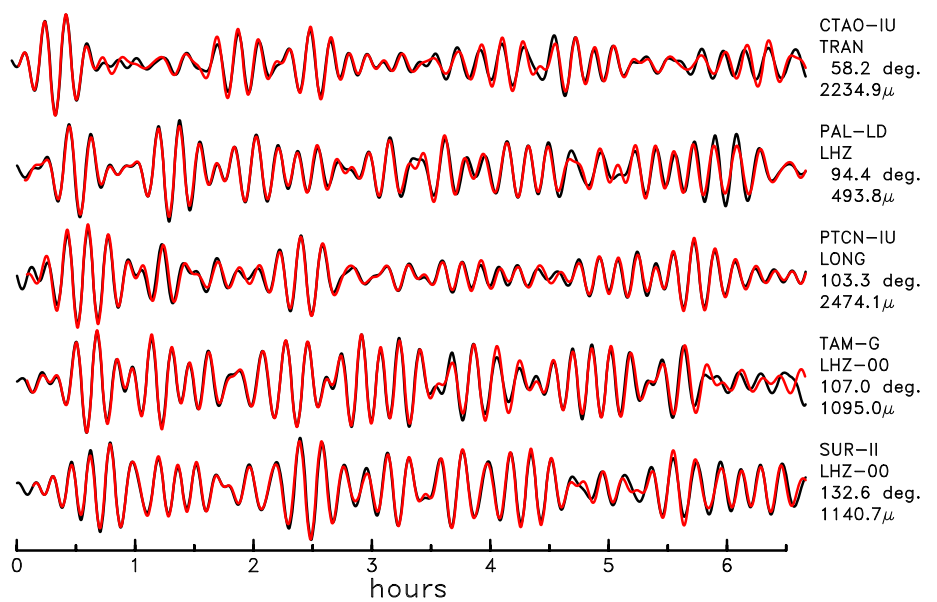

Fig. 3. Waveform fits for the $M_{\mathrm{W}}=9.1$ mainshock. Displacement waveforms are filtered between 500 and $1000 \mathrm{~s}$, outside the range used in the inversion. Black lines are observed seismograms and red lines are corresponding normal-mode synthetic waveforms. Timescale shows time after the mainshock hypocentral time. For each pair of traces, the station name, channel, epicentral distance, and maximum displacement are given.
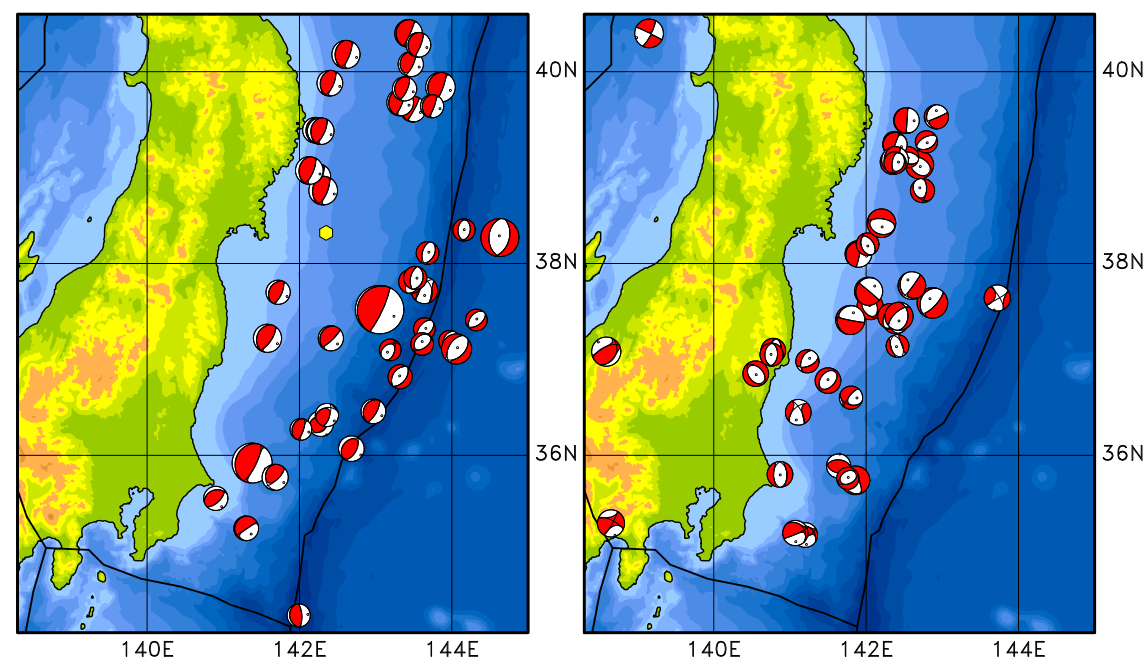

Fig. 4. Maps showing (left) focal mechanisms of the mainshock and conforming aftershocks, and (right) non-conforming aftershocks. The focal mechanisms are plotted at the centroid locations, and their size is proportional to the moment magnitude. Yellow hexagon in left map shows mainshock epicenter. Plate boundaries are from Bird (2003).

\subsection{Aftershocks}

The remaining 81 earthquakes for which we present results here are aftershocks that occurred in the 25 days following the mainshock. We note that the two largest aftershocks occurred during the hour following the mainshock (Fig. 1). The aftershock sequence shows a striking pattern, with a large number of focal mechanisms different from that of the mainshock and which cannot be explained by additional slip on the interplate contact. A subset of these aftershocks is related to the frequently observed pattern of triggered intraplate normal-faulting activity near the outer rise of the subducting plate, and we include these events, together with the interplate seismicity, in a category we label 'conforming aftershocks'. We choose to structure the description of our results here around (1) two early, large aftershocks; (2) the distribution of conforming aftershocks; and (3) the distribution of non-conforming aftershocks.

2.3.1 Two early aftershocks Twenty-nine minutes after the mainshock, at 06:15:39.6, a $M_{\mathrm{W}}=7.9$ earthquake occurred approximately $250 \mathrm{~km}$ south of the mainshock epi- center, and $\sim 200 \mathrm{~km}$ southwest of the mainshock centroid. The earthquake has a focal mechanism consistent with interplate slip (Fig. 4). It is possible that the rupture areas of the mainshock and this event are contiguous, though the large distance of the aftershock from the mainshock centroid makes this relationship unclear. The CMT analysis of the $M_{\mathrm{W}}=7.9$ aftershock was complicated by the interference of waves from the mainshock, but the intermediateperiod surface-wave arrivals at many stations were sufficiently isolated in time for a successful analysis. Figure 5 shows representative fits at several stations.

A second large aftershock occurred thirty-nine minutes after the mainshock, at 06:25:50.2. This $M_{\mathrm{W}}=7.6$ normalfaulting earthquake is located east of the mainshock within the Pacific plate and should be classified as an outer-rise earthquake. We note that this earthquake has an epicenter very close to that of a $M_{\mathrm{W}}=7.0$ normal-faulting outer-rise event that followed the $2005 M_{\mathrm{W}}=7.2$ interplate event mentioned earlier.

These two earthquakes are, as of 2011/04/05, the only 


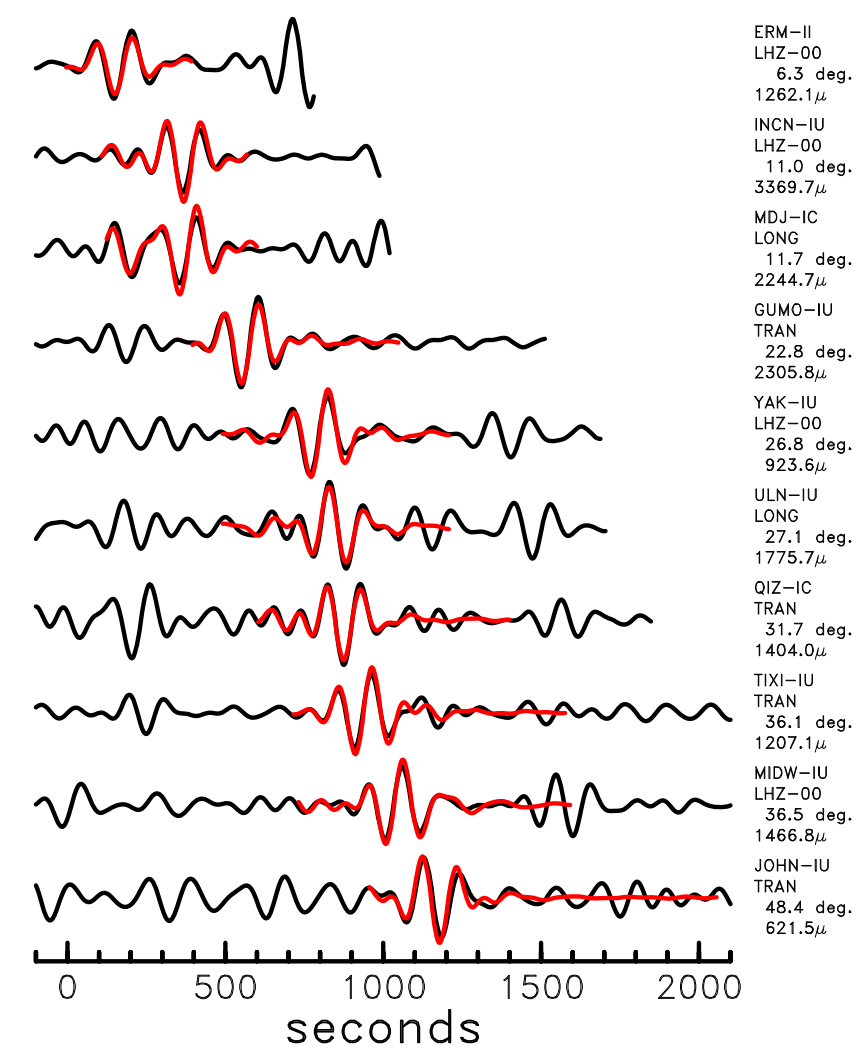

Fig. 5. Waveform fits for the $M_{\mathrm{W}}=7.9$ aftershock on March 11. Displacement waveforms are filtered between 75 and $200 \mathrm{~s}$. Black lines are observed seismograms and red lines are corresponding synthetic waveforms. Timescale shows time after the earthquake hypocentral time. For each pair of traces, the station name, channel, epicentral distance, and maximum displacement are given.

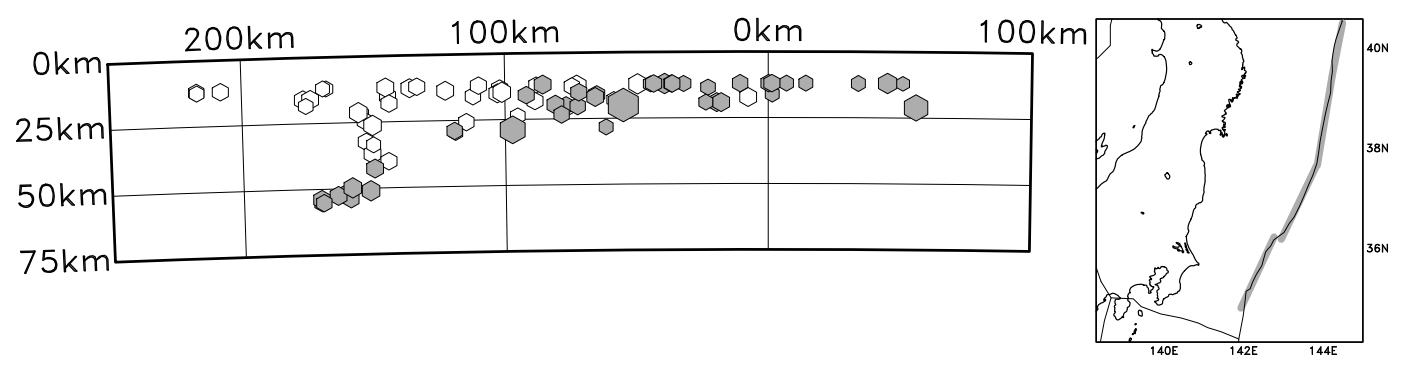

Fig. 6. Cross section showing centroid depths for mainshock and aftershocks with conforming (gray hexagons) and non-conforming (white hexagons) focal mechanisms. The size of the symbols is proportional to the moment magnitude. The cross section shows meridional distance perpendicular to the subduction trench, where the location of the trench is approximated as shown by the thick gray lines in the map. The down-dip direction is to the left in the cross section. Plate boundaries are from Bird (2003).

earthquakes in the Tohoku aftershock sequence that we find to have $M_{\mathrm{W}} \geq 7.0$.

2.3.2 Conforming aftershocks Aftershocks with shallow-dipping thrust-faulting mechanisms consistent with interplate slip extend from the triple junction in the south, around $34.5^{\circ} \mathrm{N}$, to $40.5^{\circ} \mathrm{N}$. The distribution of conforming aftershocks is shown in map view in Fig. 4, and in cross section in Fig. 6. The deepest earthquakes occur north of the mainshock at $\sim 55 \mathrm{~km}$ depth. There is a notable absence of thrust-faulting aftershocks up dip from the mainshock hypocenter, both to the north and to the south, over a total distance of $\sim 400 \mathrm{~km}$ along the strike of the plate boundary. This, together with the up-dip location of the centroid of moment, could indicate complete strain relaxation across this portion of the plate interface.

Normal-faulting activity on the seaward side of the af- tershock zone, inferred to represent triggered extensional faulting in the Pacific plate, is represented by thirteen focal mechanisms. These earthquakes are clustered near the centroid location of the mainshock, suggesting a causal relationship to the maximum or center of slip on the plate interface.

2.3.3 Non-conforming aftershocks The subset of non-conforming aftershocks includes earthquakes in a variety of settings and with different focal mechanisms (Fig. 4). All of these events have locations (Fig. 4) and depths (Fig. 6) that suggest intraplate faulting in the overriding plate, except for the strike-slip earthquake near the trench, which we infer to be associated with tension in the Pacific plate.

Three earthquakes occurred far west of the rupture area: one is a strike-slip earthquake located off the west coast of 
northern Honshu, in the source region of the $1983 M_{\mathrm{W}}=$ 7.7 Japan Sea (Akita-Oki) thrust earthquake (Fukuyama and Irikura, 1986). A second is located near the 2004 Chuetsu earthquake sequence (Hikima and Koketsu, 2005), and has a reverse-faulting focal mechanism similar to those earthquakes. A third event is located northwest of the Izu penisula and has a strike-slip focal mechanism similar to previous earthquakes in this area.

The remaining non-conforming earthquakes occur above the interplate rupture zone, with a prevalence of normalfaulting mechanisms with a variety of fault strikes. The region close to and between the mainshock hypocenter and centroid is characterized by a particularly complex pattern of strain release. To the north, several thrust-faulting earthquakes with shallowly dipping nodal planes are located over a range of depths less than $40 \mathrm{~km}$, while the depth to the plate interface below their epicenters is $\sim 50 \mathrm{~km}$. These events thus reflect faulting on near-vertical or nearhorizontal planes in the overriding plate. To the south of the mainshock centroid, a cluster of five focal mechanisms indicates trench-perpendicular extension in the overriding plate. Near the southern end of the aftershock zone, two mechanisms show northwest-southeast compression, possibly associated with the Sagami trough thrust fault (e.g., Stein et al., 2006).

\section{Discussion and Conclusion}

The 2011 Tohoku Earthquake is the best-observed great earthquake, and it will undoubtedly become one of the most studied, owing both to its size and the enormous losses associated directly with the earthquake as well as with the tsunami that it generated. The results presented here, compiled less than four weeks after the occurrence of the mainshock, are limited to near-real-time seismological analyses of the larger earthquakes in the sequence. These results establish some basic parameters and characteristics of the Tohoku sequence, and we believe they will be useful in informing future investigations and directions of research.

The mainshock was very well recorded on the GSN and other modern seismological instruments around the world. Our analysis at long periods indicates a relatively simple and compact source, especially when compared with the $2004 M_{\mathrm{W}}=9.3$ Sumatra earthquake which, even at long periods, showed complexities associated with changing rupture geometry and segmentation (e.g., Tsai et al., 2005). Our analysis of the Tohoku mainshock gives a moment magnitude $M_{\mathrm{W}}=9.1$, making this the fourth-largest earthquake of the last 100 years.

The two largest aftershocks (as of 2011-04-05) occurred within one hour of the mainshock. A $M_{\mathrm{W}}=7.9$ event occurred near the southern end of the aftershock zone and presumed mainshock rupture area and may represent a con- tiguous extension of this rupture area. A $M_{\mathrm{W}}=7.6$ normal-faulting outer-rise earthquake, located northeast of the mainshock centroid, indicates a rapid lithospheric response to the changing stresses in the Pacific plate seaward of the maximum slip on the interplate fault.

A large fraction of the aftershocks analyzed here can be characterized as non-conforming, in that they occur neither on the interplate fault nor as normal-faulting extensional events in the subducting plate. The nature of the causal relationship between the mainshock and these aftershocks remains to be investigated, including the extent to which stress-transfer models can explain their triggering (e.g., Toda and Enescu, 2011).

CMT results for the 88 earthquakes analyzed here are available in standard GCMT formats from the Special Event Studies page on our web site: www.globalcmt.org/Events.

Acknowledgments. The GSN data analyzed in this study were collected and distributed by the Incorporated Research Institutions for Seismology (IRIS), the USGS, and the Geoscope, Geofon and Mednet projects, as well as the GLISN project and the Lamont Cooperative Seismographic Network. This research was supported by NSF Grants EAR-08-24694 and EAR-09-44055. We thank two anonymous reviewers for helpful comments on the manuscript.

\section{References}

Arvidsson, R. and G. Ekström, Global CMT analysis of moderate earthquakes, $M_{W} \geq 4.5$, using intermediate period surface waves, Bull. Seismol. Soc. Am., 88, 1003-1013, 1998.

Bird, P., An updated digital model of plate boundaries, Geochem. Geophys. Geosyst., 4, 1027, doi:10.1029/2001GC000252, 2003.

Dziewonski, A. M., T.-A. Chou, and J. H. Woodhouse, Determination of earthquake source parameters from waveform data for studies of global and regional seismicity, J. Geophys. Res., 86, 2825-2852, 1981.

Ekström, G., Global detection and location of seismic sources using surface waves, Bull. Seismol. Soc. Am., 96, 1201-1212, 2006.

Ekström, G., A. M. Dziewonski, N. N. Maternovskaya, and M. Nettles, Global seismicity of 2003: centroid-moment-tensor solutions for 1087 earthquakes, Phys. Earth Planet. Inter., 148, 327-351, 2005.

Fukuyama, E. and K. Irikura, Rupture process of the 1983 Japan Sea (Akita-Oki) earthquake using a waveform inversion method, Bull. Seismol. Soc. Am., 76, 1623-1640, 1986.

Hikima, K. and K. Koketsu, Rupture processes of the 2004 Chuetsu (mid-Niigata prefecture) earthquake, Japan: A series of events in a complex fault system, Geophys. Res. Lett., 32, L18303, doi:10.1029/ 2005GL023588, 2005.

Stein, R. S., S. Toda, T. Parsons, and E. Grunewald, A new probabilistic seismic assessment for greater Tokyo, Phil. Trans. R. Soc. Lond. A, 364, doi:10.1098/rsta.2006.1808, 2006.

Toda, S. and B. Enescu, Rate/state Coulomb stress transfer model for the CSEP Japan seismicity forecast, Earth Planets Space, 63, 171-185, 2011.

Tsai, V. C., M. Nettles, G. Ekström, and A. M. Dziewonski, Multiple CMT source analysis of the 2004 Sumatra earthquake, Geophys. Res. Lett., 32, L17304, 2005.

M. Nettles (e-mail: nettles@1deo.columbia.edu), G. Ekström, and H. C. Koss 